\title{
Applicability of the Electro-Vectorcardiogram in Current Clinical Practice
}

\author{
Carlos Alberto Pastore, ${ }^{\bullet}$ Nelson Samesima, Horacio Gomes Pereira Filho, Nancy Maria Martins de Oliveira Tobias, \\ Bruna Affonso Madaloso, Mirella Esmanhotto Facin \\ Instituto do Coração (InCor) do Hospital das Clínicas da Faculdade de Medicina da Universidade de São Paulo (FMUSP), São Paulo, SP - Brazil
}

\begin{abstract}
The electrocardiogram (ECG) has been reinvigorated by the identification of electrical alterations that were not definitely clarified before. In this context, and mainly regarding the definition of arrhythmogenic substrates, the association of the ECG with the vectorcardiogram (VCG) has gathered much more information about the cardiac electrical phenomena, thus allowing us to differentiate potentially fatal cases from benign ones. Obtaining a VCG concomitantly with the performance of an ECG has led to a significant gain in the definition of extremely sophisticated pathologies, which function suffer some type of structural or dynamic alterations, involving either the reduction or enhancement of ionic channels and currents.
\end{abstract}

The classic aspects of the ECG/VCG association in the differential diagnosis of myocardial infarctions, conduction disorders, atrial and ventricular hypertrophies, and the correlations between these electrical disorders are still valid and assertive. The association of these pathologies is further clarified when they are seen through the ECG/VCG dyad.

The three-dimensional spatial orientation of both the atrial and the ventricular activity provides a far more complete observation tool than the ECG linear form. The modern analysis of the ECG and its respective VCG, simultaneously obtained by the recent technique called electro-vectorcardiogram (ECG/ VCG), brought a significant gain for the differential diagnosis of some pathologies. Therefore, we illustrate how this type of analysis can elucidate some of the most important diagnoses found in our daily clinical practice as cardiologists.

\section{Introduction}

The study of vectorcardiography began during the 1940's and publications reached a peak between the 1960's and 1970 's, correlating this method with the heart diseases best known at that time. The great difficulty then was linked to the fact that the VCG device could not be easily moved around. The images were thus not immediately obtained, and so the

\section{Keywords}

Electrocardiography/methods; Vectocardiography/methods; Electrophysiological Phenomena; Internal Medicine/methods

Mailing Address: Carlos Alberto Pastore •

Av. Dr. Eneas de Carvalho Aguiar, 44 AB. Postal Code 05403-000, Cerqueira Cesar, São Paulo, SP - Brazil

E-mail: ecg pastore@incor.usp.br

Manuscript received September 19, 2018, revised manuscript January 10, 2019, accepted February 13, 2019 vectorcardiogram was a tool to be used a posteriori to resolve doubts about specific electrocardiograms in some special situations. Additionally, the advent of echocardiography and its later improvement, as well as the emergence of computed tomography and magnetic resonance imaging, led to a decreased use of both the electrocardiogram and, mainly, of the vectorcardiogram from the 1980's until the end of the 1990 's. This temporal gap, associated to a diminished interest in electrovectorcardiography, resulted in a significant decrease in the number of cardiology centers capable of performing and interpreting a vectorcardiogram.

However, with the development of invasive electrophysiology (electroanatomic mapping), genetics and molecular biology, many electrical conditions have been unveiled, resulting in the identification of their clinical/electrocardiographic patterns, since such conditions can lead to sudden death. ${ }^{1-7}$

The technological developments seen during the 1990s also affected electrovectorcardiography. The sophistication brought by the use of computers, algorithmic systems and Fourier transforms allowed us to obtain vectorcardiographic information in a much simpler and quicker form, in color, and as three-dimensional images.

The electrocardiogram (ECG) was therefore reinvigorated by the identification of electrical alterations that had not yet been definitely observed, so that from the year 2000 until the present decade an increasing number of publications related to electrovectorcardiography has been observed. In this context, and mainly regarding the definition of arrhythmogenic substrates, it was observed that the association of the ECG and the vectorcardiogram (VCG) methods could provide much more information about the cardiac electrical phenomena, thus increasing its employment and allowing us to differentiate potentially fatal cases from benign ones. ${ }^{8-10}$

We now find ourselves in a moment where the performance and reading of the vectorcardiogram is carried out in just a few specific centers around the world. Moreover, our team is involved with the teaching of electrocardiography to undergraduate and postgraduate students in the medical area. Therefore, we feel there is an urgent need to teach vectorcardiography, considering that its spatial visualization of the cardiac electrical activation makes it a lot easier to understand and memorize the basic and more complex electrocardiographic notions. ${ }^{11}$

Obtaining a VCG concomitantly with the performance of an ECG has led to a significant gain in the definition of extremely sophisticated pathologies, of which genetic mutations cause their function to suffer some type of structural or dynamic alterations, involving either the reduction or enhancement of ionic channels and currents. 
The classic aspects of the ECG/VCG association in the differential diagnosis of myocardial infarctions, conduction disorders, atrial and ventricular hypertrophies, and the correlations between these electrical disorders are still valid and assertive. ${ }^{12,13}$ The association of these pathologies is further clarified when they are seen through the ECG/VCG dyad. (Figure 1)

Based on the abovementioned facts, during the last decade we were able to develop the performance of the binomial electrovectorcardiogram in the context of the most varied pathologies. This binomial can add sophistication to the already known clinical entities, in addition to a greater accuracy of the recent electrocardiographic definitions (such as Brugada, early repolarization, etc.)

Our experience, both academic and scientific, led us to join these new ECG/VCG acquisitions, and to open a window into the observation of the electrical phenomena of the heart. The literature has shown that the more sophisticated vectorcardiogram makes it easier for us to observe punctual phenomena that are not defined by the ECG.

\section{Limitations}

Because there are only a few centers that are capable of performing routine vectorcardiography, there remains no doubt that this comparative study requires specific training, just like any other diagnostic method, through didactic bibliography and distance learning material. The purpose of this publication is guided by the acknowledgement of this situation.

\section{The electrovectorcardiography binomial}

The experience with the VCG during these last decades shows the greater specificity and sensitivity of this method to detect the subtleties of these diagnoses. In comparison with the ECG, the VCG shows some advantages; however, when in association, they can help us differentiate between some very ordinary situations in clinical practice.

The three-dimensional spatial orientation of both the atrial and the ventricular activity provides a far more complete observation tool than the linear form of the ECG. The modern analysis of the ECG and its respective VCG, simultaneously obtained by the recent technique called electro-vectorcardiogram (ECG/VCG), brought a significant gain for the differential diagnosis of some

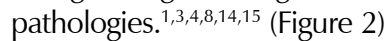

The electro-vectorcardiographic analysis is very rich and consistent for the diagnosis of myocardial infarctions (MI), since the difficulties in defining pathological $\mathrm{Q}$ waves or the loss of R waves in the ECG can be very clearly visualized in the ECG/VCG. This association helps us to define the real changes in the direction and orientation of the vectorcardiographic loops created by the areas of myocardial infarction, in both the transverse and the frontal planes. ${ }^{16-18}$ (Figure 3)

Another important differential aspect obtained by the electro-vectorcardiogram is the investigation of the presence of a myocardial infarction area in the inferior wall, of a left superior fascicular block, or the association of both pathologies. The association of Mls with the presence of fascicular or troncular blocks can be fully characterized by the ECG/VCG association. The inferior Mls with a left anterosuperior fascicular block (LASFB), and the anterior MIs with a right bundle-branch block (RBBB) are typical examples of the importance of the ECG/VCG association for a differential diagnosis. ${ }^{19,20}$ (Figures $3 \mathrm{~A}$ and $4 \mathrm{~A}$ and $\mathrm{B}$ )

The spatial orientation of the fascicular blocks can be better understood through the electro-vectorcardiogram. The septal vector orientation and the direction of the vectorcardiographic loop activation neatly characterize the fascicular blocks and their associations through the ECG/VCG, since they define the electrical path of this phenomenon, thus characterizing exactly the position of the blocks. ${ }^{21-24}$ (Figures $4 \mathrm{~A}$ and 5(A and $\mathrm{B}$ )

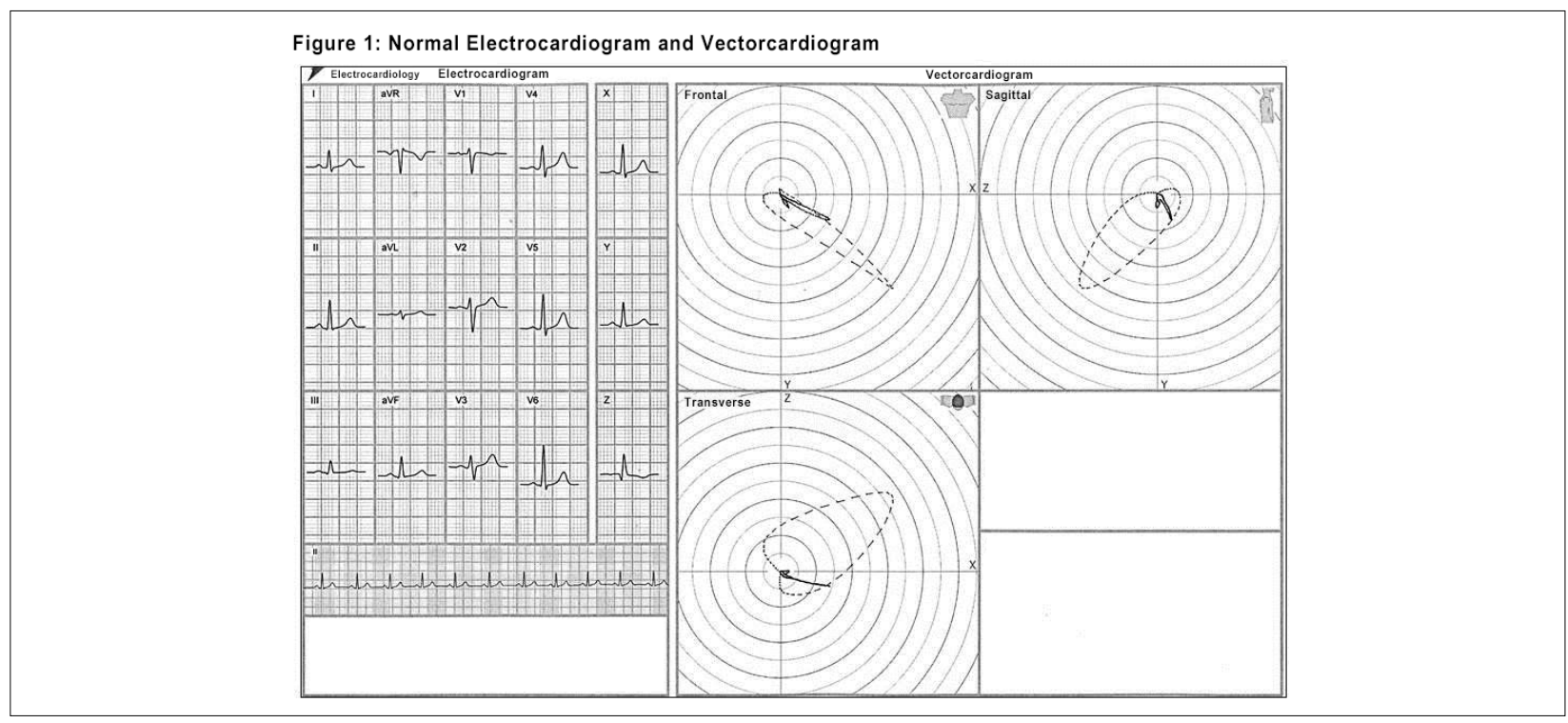

Figure 1 - Electrocardiogram vs. Vectorcardiogram. 


\section{Review Article}

\section{Figure 2: Orthogonal planes}

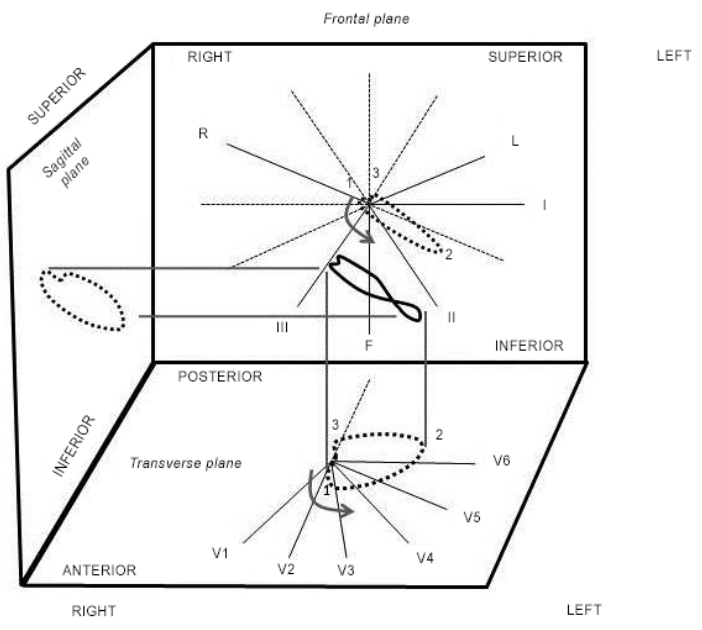

Figure 2 - Electrical activation of the heart and its projection in the three spatial planes, thus giving origin to the vectorcardiographic loops in the respective planes.

The VCG complements the ECG in the analysis of acute myocardial infarctions and makes the differential diagnosis of the associations with blocks and chamber hypertrophies. There is no doubt that the most ordinary situations in the cardiological routine, such as absent or exaggerated $\mathrm{R}$ waves from $\mathrm{V} 1$ to $\mathrm{V} 3$, require a more sophisticated definition in this region that depicts many expressions of different pathologies. Therefore, in this region the ECG/VCG is capable of characterizing the presence of: ${ }^{22-27}$ (Figures 5B, 6[A, B, C and D])

a) Left anteromedial fascicular block (LMFB)

b) Right ventricular hypertrophy (RVH)

c) Lateral infarction

d) Ventricular pre-excitation syndrome (WPW)

e) Brugada syndrome

The ECG/VCG is the gold standard to identify complete and fascicular blocks, because it can differentiate them either in isolation or in association with other blocks. The electrical path marked by the ventricular activation loops can identify the blocks, as well as other associations. ${ }^{21,23,28}$ (Figure 7)

The end-conduction delays, previously denominated incomplete right bundle-branch blocks, are neatly defined by the ECG/VCG. These findings can be mistaken for the left phenomena and also can mimic a myocardial infarction area. Thus, the association of ECG/VCG solves the doubts that arise from the presence of these delays, which can be either the variants from the normal, or even suggest a conduction disorder in specific areas of the right ventricle.

The presence of the end-conduction delay (ECD) is clarified in the ECG/VCG by the $S_{1} S_{2} S_{3}$ pattern, with the $S$ wave in $D_{2}$ greater than the one in $D_{3^{\prime}} q R$ in aVR and presence of $S$ wave from $\mathrm{V}_{1}$ to $\mathrm{V}_{6}$. The $\mathrm{ECG} / \mathrm{VCG}$ confirms the $\mathrm{ECD}$ position backwardly and to the right in the transverse plane, and upwardly and to the right in the frontal plane. ${ }^{25}$ (Figure 8)
One of the definitive identifications obtained by the ECG/VCG association is that of the presence of a ventricular pre-excitation (WPW). The presence of the delta wave is very clearly seen in the beginning of the QRS loop by the proximity of the comets at the onset of the QRS loop, characterizing the delay caused by the accessory pathway, thus also establishing the position of the anomalous bundle at the valvular annulus. ${ }^{26}$ (Figure 9 [A and B])

One of the most recent diagnostic achievements of the ECG/VCG refers to the criteria to establish Brugada syndrome patterns, as well as the early repolarization (ER) phenomenon. It is important to emphasize that, in typical cases, there are no difficulties to make the electro-vectorcardiographic identification of both conditions. Due to the severity of the first, to the variability of the second between normal cases and other pathologies, and also to the possibility of having an early repolarization pattern located in a more anterior area, it became essential to make an adequate distinction between them. From the ECG/VCG viewpoint, there are no guidelines set to date to identify J-wave abnormalities. Specific ECG/VCG patterns of the J-wave abnormalities, namely the Brugada syndrome $(\mathrm{BrS})$, and the early repolarization pattern (RP) were studied by our research team. An important qualitative and quantitative analysis of the ECG/VCG was carried out in all the study population, specifically regarding aspects of the area comprising the terminal portion of the QRS loop, the J point and the ST segment. This analysis showed a neat end-conduction delay (ECD) in all the individuals (in both the $\mathrm{BrS}$ and the RP groups). This ECD is characterized by a conduction delay greater than $10 \mathrm{~ms}$ at the final portion of the QRS in all the planes, either to the right or to the left (slowing of the comets, which tend to get closer and, eventually, to merge). 
Figure 3A: Old inferior myocardial infarction (MI)

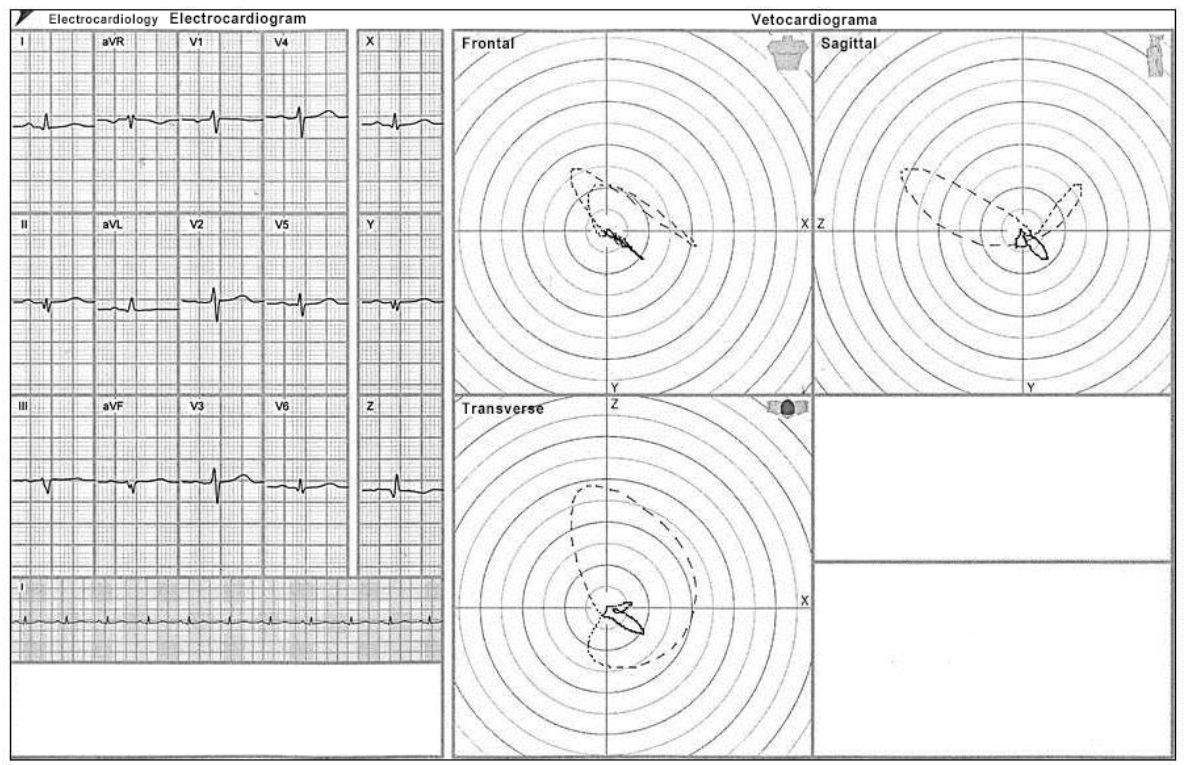

Figure 3B: Old anteroseptal MI

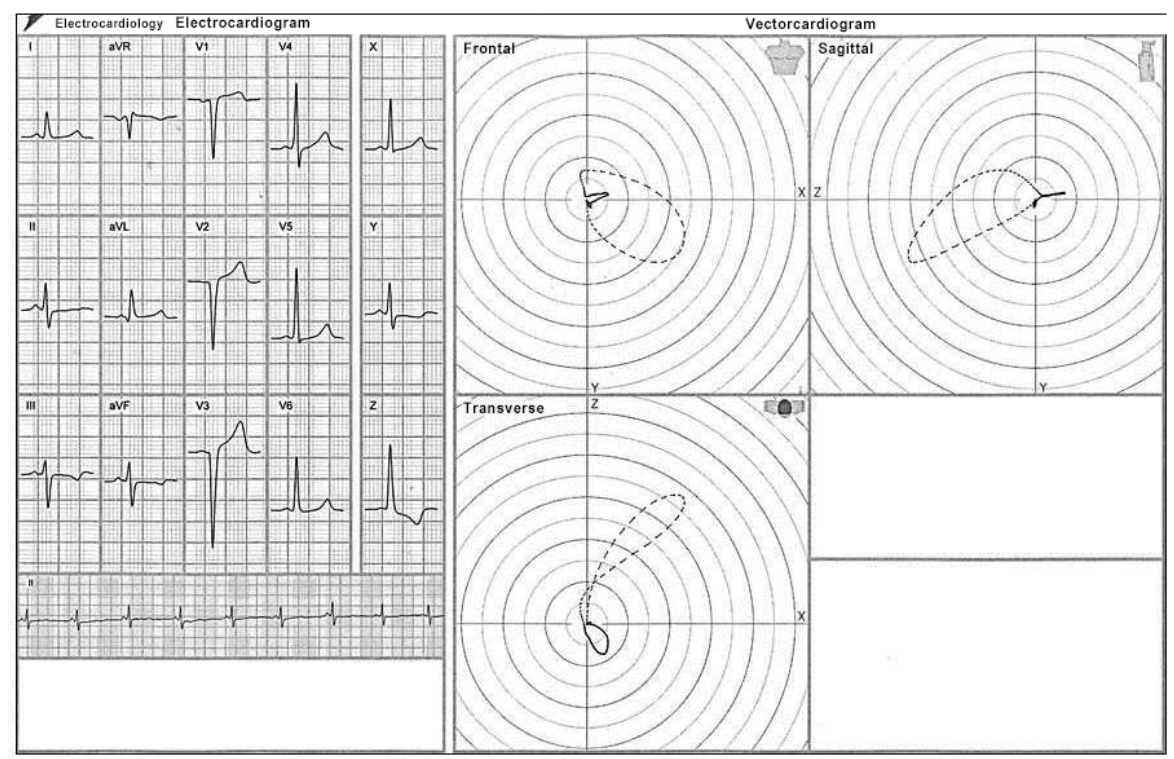

Figure 3 - (A) Presence of myocardial infarction area in the inferior wall, with QRS vectorcardiographic loop onset oriented upwardly and to the left. (B) Aspect of a large myocardial infarction area from V1 to V6 and its respective loop in the transverse plane, with anomalous activation of the septum and exaggerated backward rotation, followed by deformation of the QRS loop.

In the transverse plane, the QRS loops showed a counterclockwise rotation, with the ECD beginning posteriorly and ending anteriorly, with the main difference between the groups being the ECD position.

In BrS type 1 patients (Figure 6D) we see a counterclockwise rotation of the terminal QRS segment, J point and onset of the ST segment around the medial portion, resembling a "nose" in profile. The ECD position was in the right quadrant in all $\mathrm{BrS}$ patients and its duration was significantly longer.
A greater than or equal to $30 \mathrm{~ms}$ ECD had $100 \%$ sensitivity and $77 \%$ specificity to diagnose Brugada syndrome. The BrS group showed a break at the end of the QRS loop right after the ECD, which resembled a "nose", right before the onset of the T-wave loop. This "nose" pattern was present in all the BrS type 1 patients.

In the ER pattern ${ }^{9,25}$ (Figure 10) we see a clockwise rotation (terminal portion of the QRS) of the same segments, resembling a "fishhook". In all the ER cases the ECD position 


\section{Review Article}

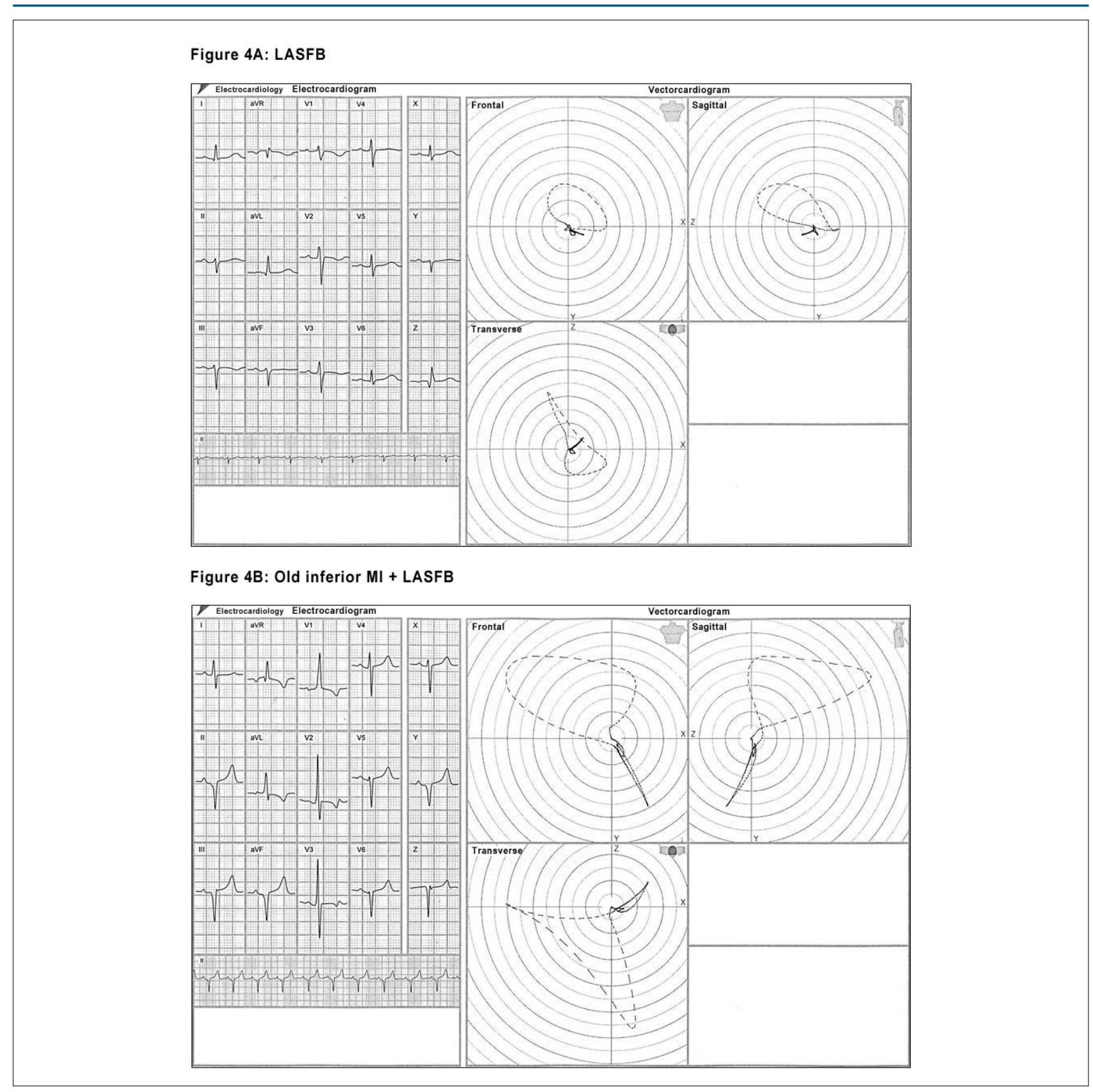

Figure 4 - Aspects of the VCG loops in the Inferior MI (in Fig. 3A of the previous item, note the QRS loop onset upwardly in the frontal plane, with more than 30 ms duration [15 comets]); in Figure 4A- LASFB, observe the QRS loop onset downwardly (through the posterior-inferior division), with counterclockwise rotation and the major portion of the loop oriented upwardly and to the left; and in Figure $4 B$ - LASFB + inferior MI, the association of the two entities; note that the QRS loop in the frontal plane is directed upwardly, with clockwise rotation, and after $30 \mathrm{~ms}$ it changes its orientation, with counterclockwise rotation characterizing the LASFB.

was in the left quadrant, with a shorter duration. In $100 \%$ of the ER patients, the final portion of the QRS loop showed a fishhook pattern.

Characteristic electro-vectorcardiographic aspects of the type 1 Brugada syndrome (see Figure 6D): transverse plane: QRS loop onset with counterclockwise rotation; ECD began posteriorly and ended anteriorly and in the right quadrant in all BrS patients; BrS showed a "break" at the end of the QRS loop after the ECD, in the terminal segment of the QRS loop, resembling a "nose", right before the T wave loop onset; this "nose" pattern was present in all type $1 \mathrm{BrS}$ patients, but in none of ER patients.

A very important arrhythmogenic pathology, the arrhythmogenic right ventricle cardiomyopathy (ARVC), has an almost definitive assessment tool in the electrovectorcardiographic diagnosis. The end-conduction delay with low voltage and long duration to the right (forward or slightly backwards) characterizes the phenomenon with great accuracy, with the differential diagnosis being very important, since this pathology may lead to severe arrhythmias. (Figure 11) 
Figure 5A: LPIFB

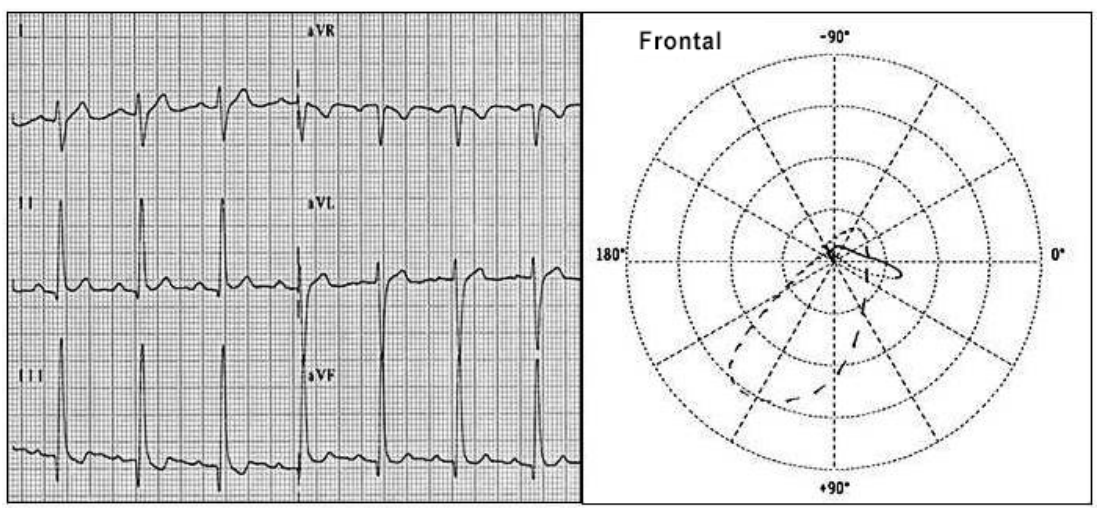

Figure 5B: LAMFB

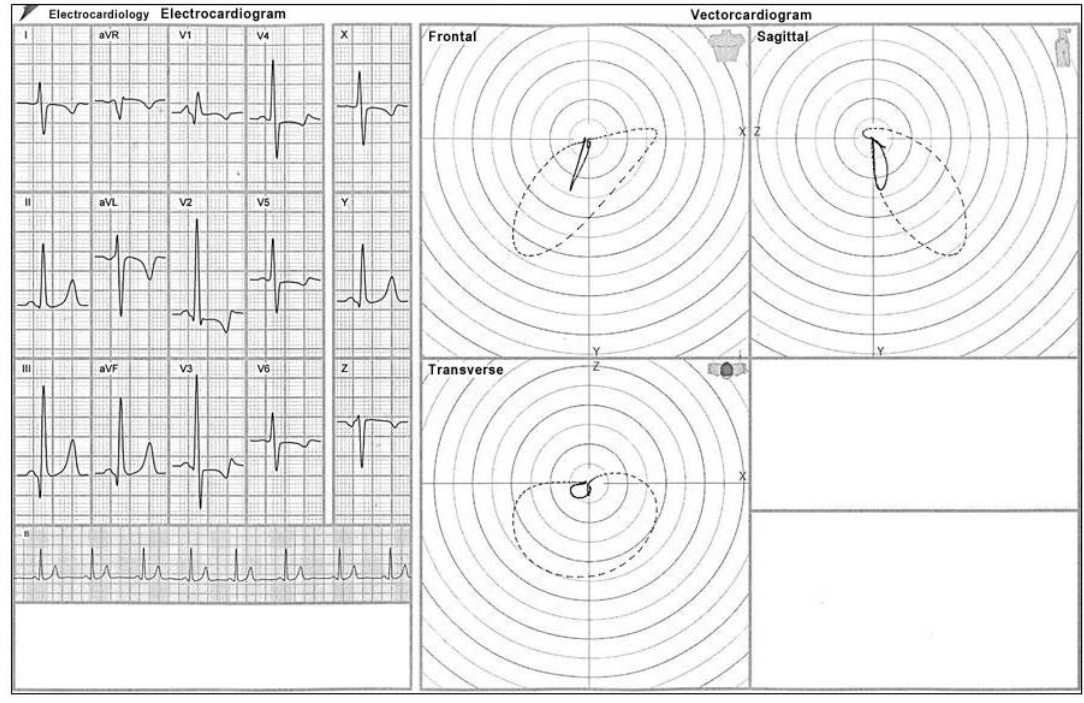

Figure 5 - Electro-vectorcardiographic aspects of LASFB - Fig. 4A of the previous item, left posteroinferior fascicular block (LPIFB) - Figure $5 A$ and left anteromedial fascicular block (LAMFB) - Figure $5 B$.

ARVC sometimes presents with an aspect similar to the RBBB, although with a very low voltage that is different from that block. It can also show an ECD aspect on the right and be slightly backwards. The presence of a negative $\mathrm{T}$ wave in $\mathrm{V}_{1}, \mathrm{~V}_{2}, \mathrm{~V}_{3}$ and left posteriorly located in the transverse plane of the ECG/VCG is crucial for an accurate diagnosis.

The ECG/VCG has been used in the follow-up of the new arrhythmia ablation procedures, as in Brugada syndrome, where it cooperates in characterizing the successful cases and differentiating them from the unsuccessful procedures. The initial and already consecrated experience of the ECG/VCG in the ventricular pre-excitation and in the ablation procedures for this syndrome has brought subsidies for the recently described observations. The Brugada syndrome has shown to be very dynamic regarding its arrhythmogenic substrate, and the ECG/VCG follow-up can be very useful to define this process. ${ }^{29,30}$ (Figure 12).

\section{Author contributions}

Conception and design of the research: Pastore CA, Samesima N, Facin ME; Acquisition of data: Pastore CA, Samesima N, Pereira Filho HG, Madaloso BA, Facin ME; Analysis and interpretation of the data and Critical revision of the manuscript for intellectual content: Pastore CA, Samesima N, Pereira Filho HG, Tobias NMMO, Madaloso BA, Facin ME; Writing of the manuscript: Pastore CA, Samesima N, Madaloso BA.

\section{Potential Conflict of Interest}

No potential conflict of interest relevant to this article was reported.

\section{Sources of Funding}

There were no external funding sources for this study. 


\section{Review Article}

\section{Figure 6A: Right ventricular hypertrophy}

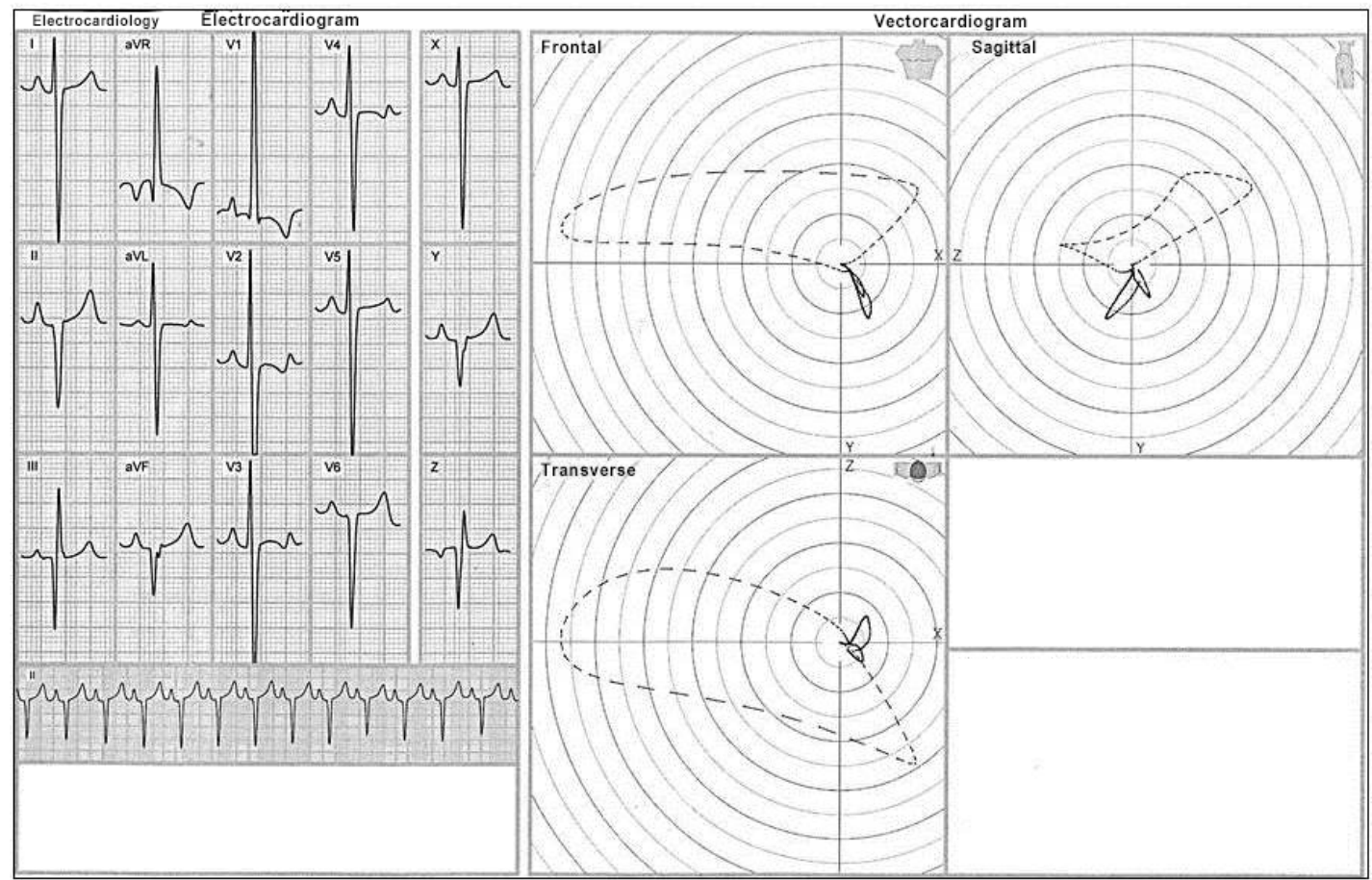

Figure 6B: Old lateral MI

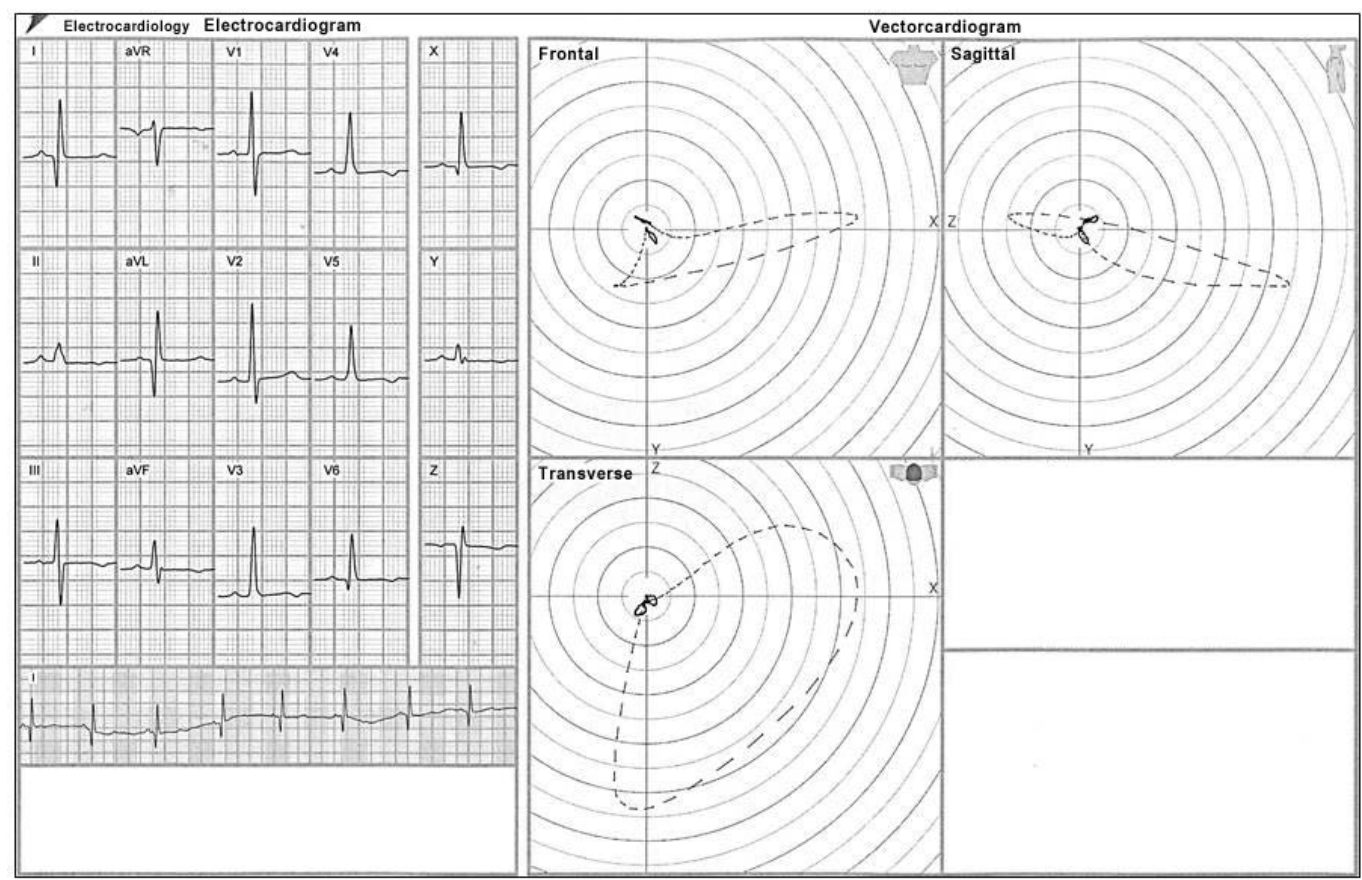

Figure 6 - Illustrations of differential diagnoses identified by the ECGNCG in different pathologies: left anteromedial fascicular block (LAMFB) - see Fig.5B; right ventricular hypertrophy $(R V H)$ - Figure $6 A$; lateral infarction - Figure $6 B$.

\section{Study Association}

This study is not associated with any thesis or dissertation work.

\section{Ethics approval and consent to participate}

This article does not contain any studies with human participants or animals performed by any of the authors. 
Figure 6C: Ventricular pre-excitation syndrome (WPW)

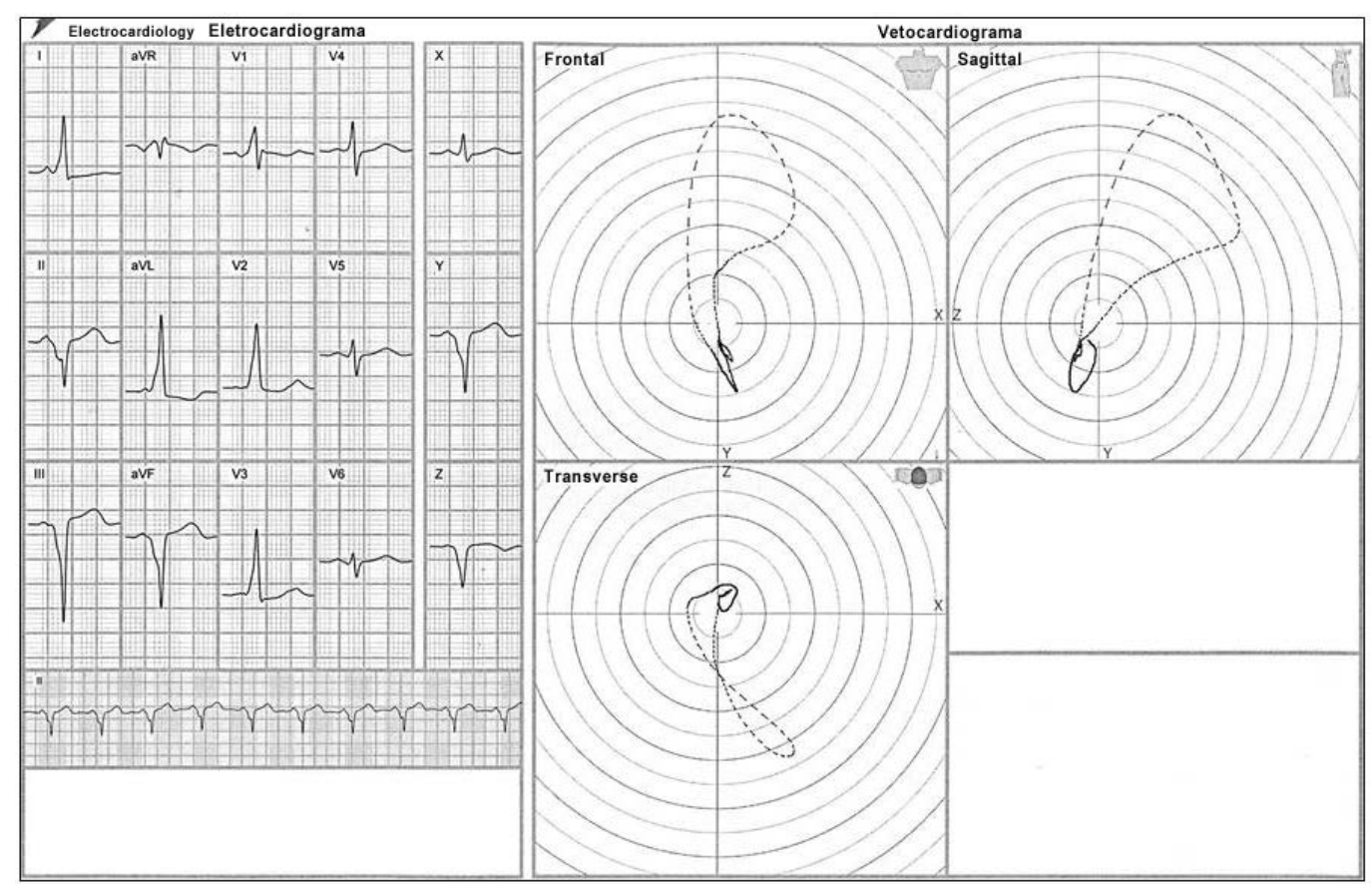

Figure 6D: Brugada syndrome

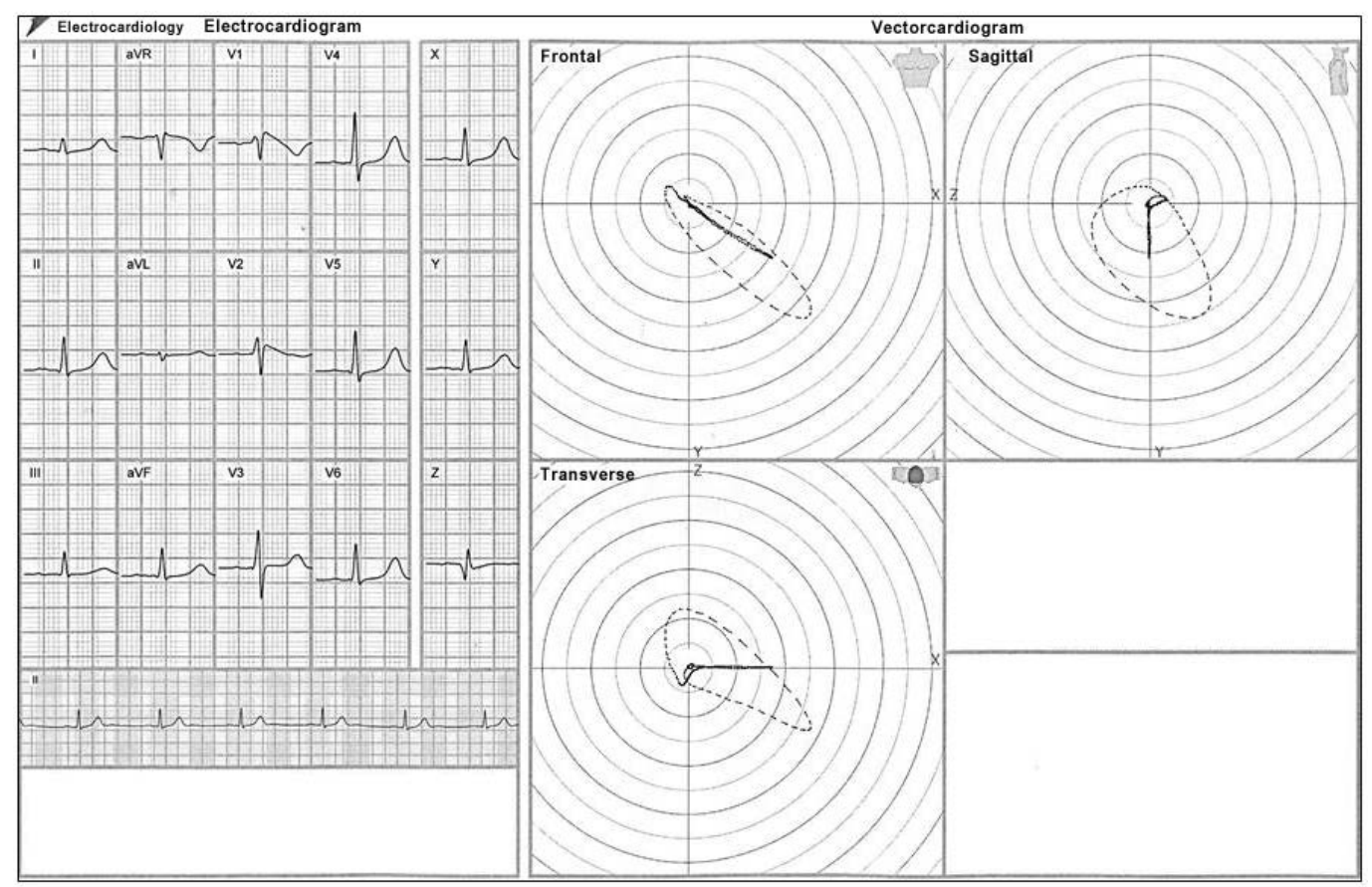

Figure 6 - Illustrations of differential diagnoses identified by the ECGNCG in different pathologies: left anteromedial fascicular block (LAMFB) - see Fig.5B; ventricular pre-excitation syndrome (WPW) - Figure 6C; Brugada syndrome - Figure 6D. 


\section{Review Article}

Figure 7: LPIFB + RBBB

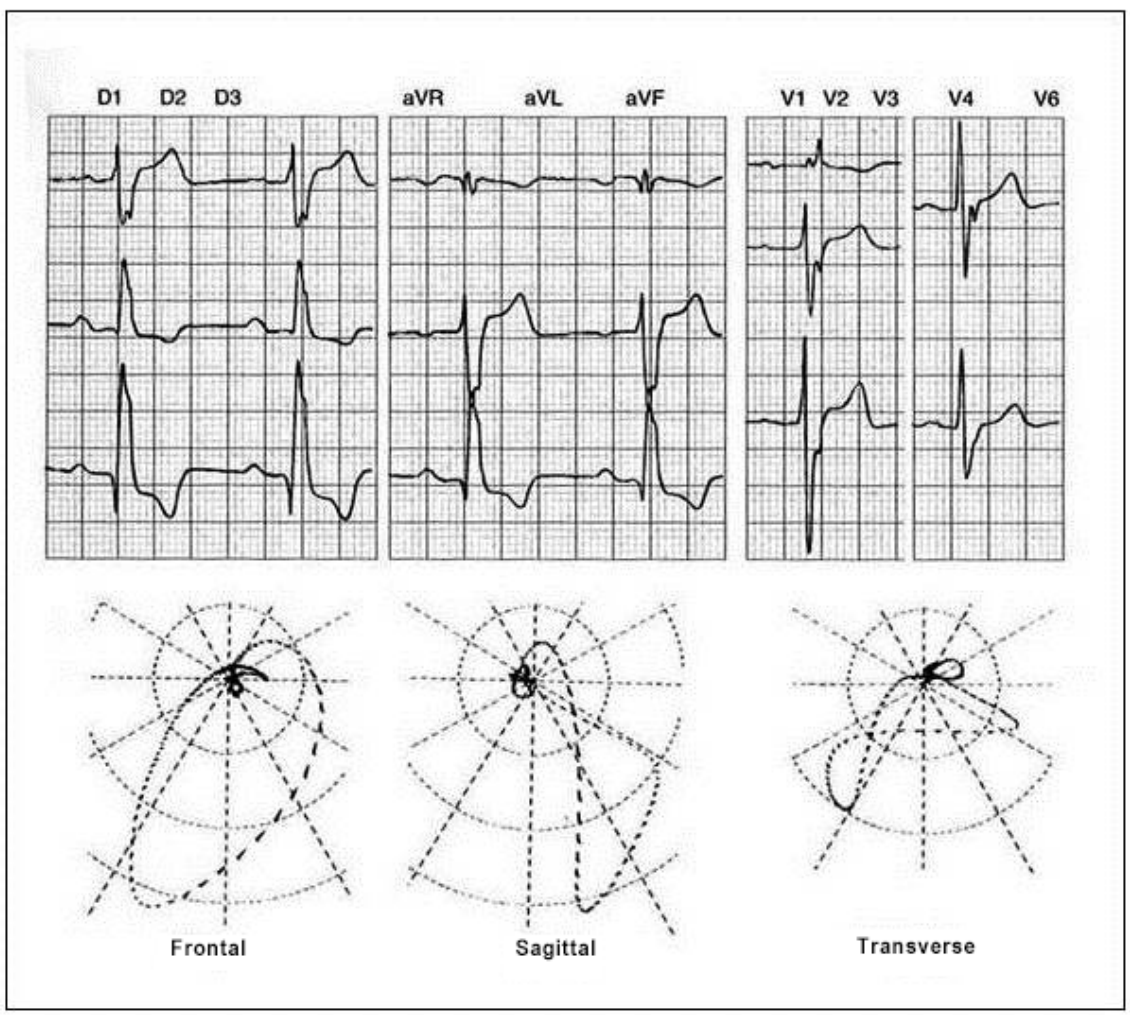

Figure 7 - Vectorcardiographic aspects of the association of LPIFB and RBBB: axis to the right in the frontal plane (LPIFB), with most of the QRS loop in the frontal plane oriented downwardly and to the left, and the QRS loop in the transverse plane, slowly ending forwardly and to the right (RBBB).

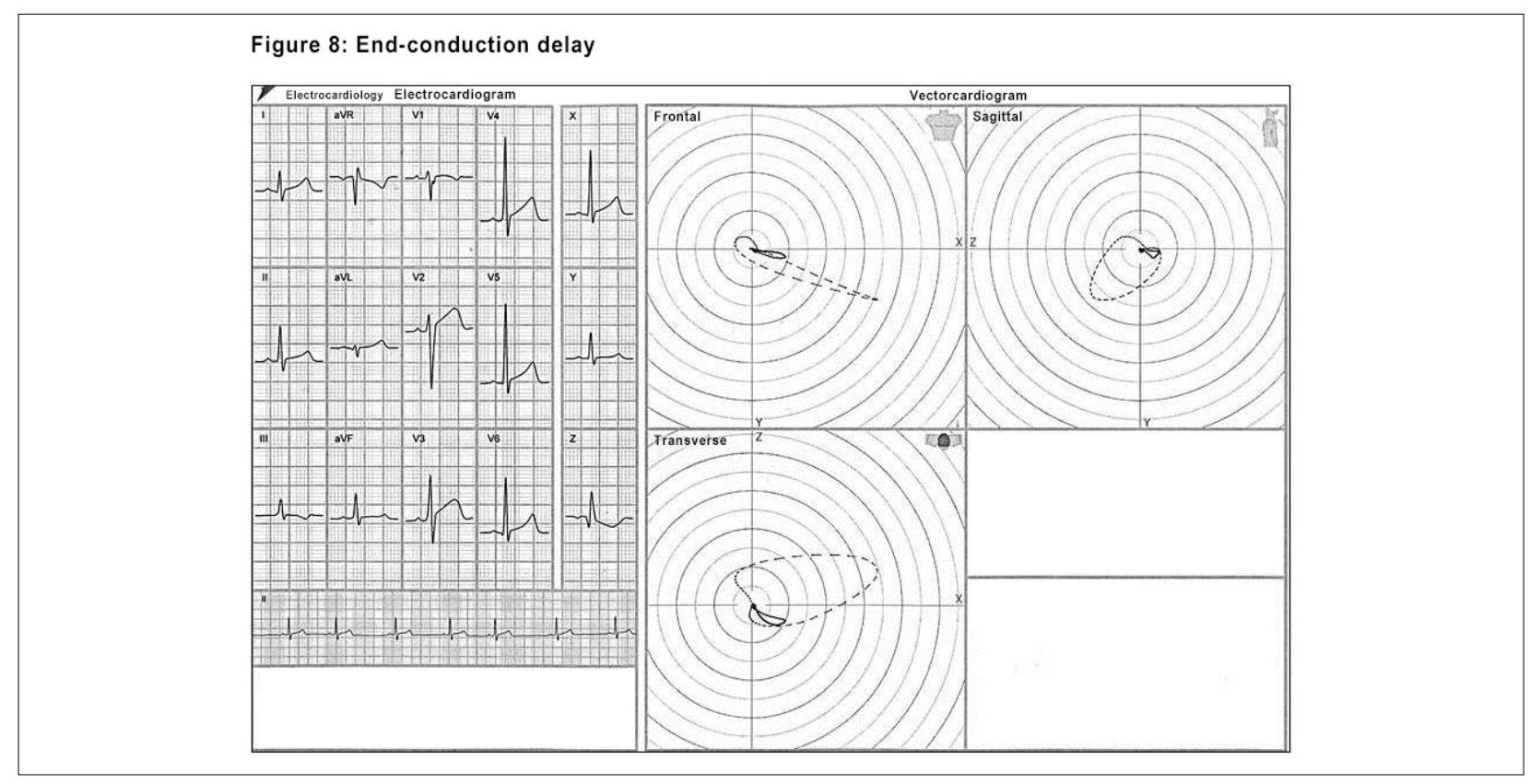

Figure 8 - Electro-vectorcardiographic aspects of the end-conduction delay. 
Figure 9A: Ventricular pre-excitation

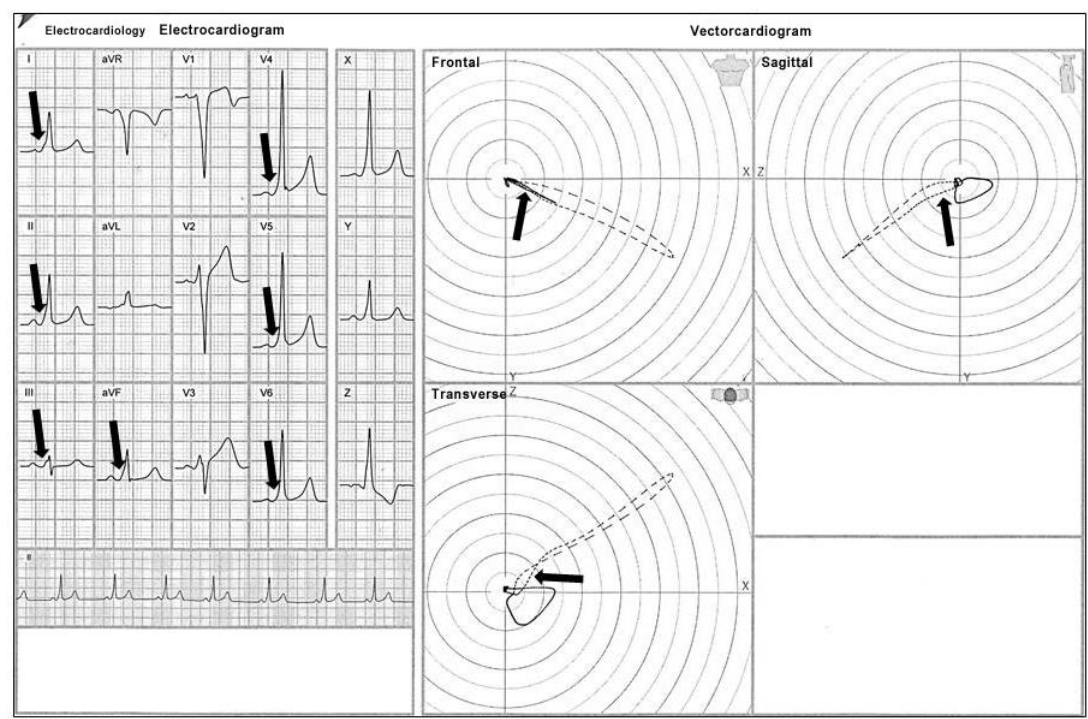

Figure 9B: Ventricular pre-excitation

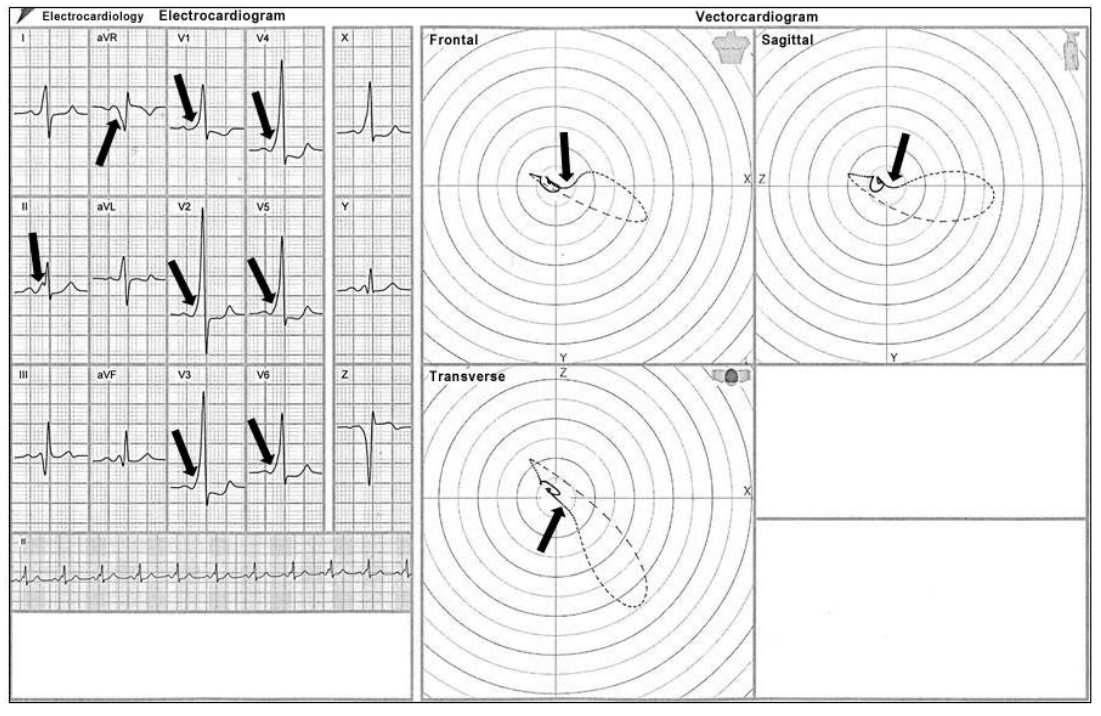

Figure 9 - (A and B). Electro-vectorcardiographic aspects of the ventricular pre-excitation, highlighting the presence of the delta wave (arrows). 


\section{Review Article}

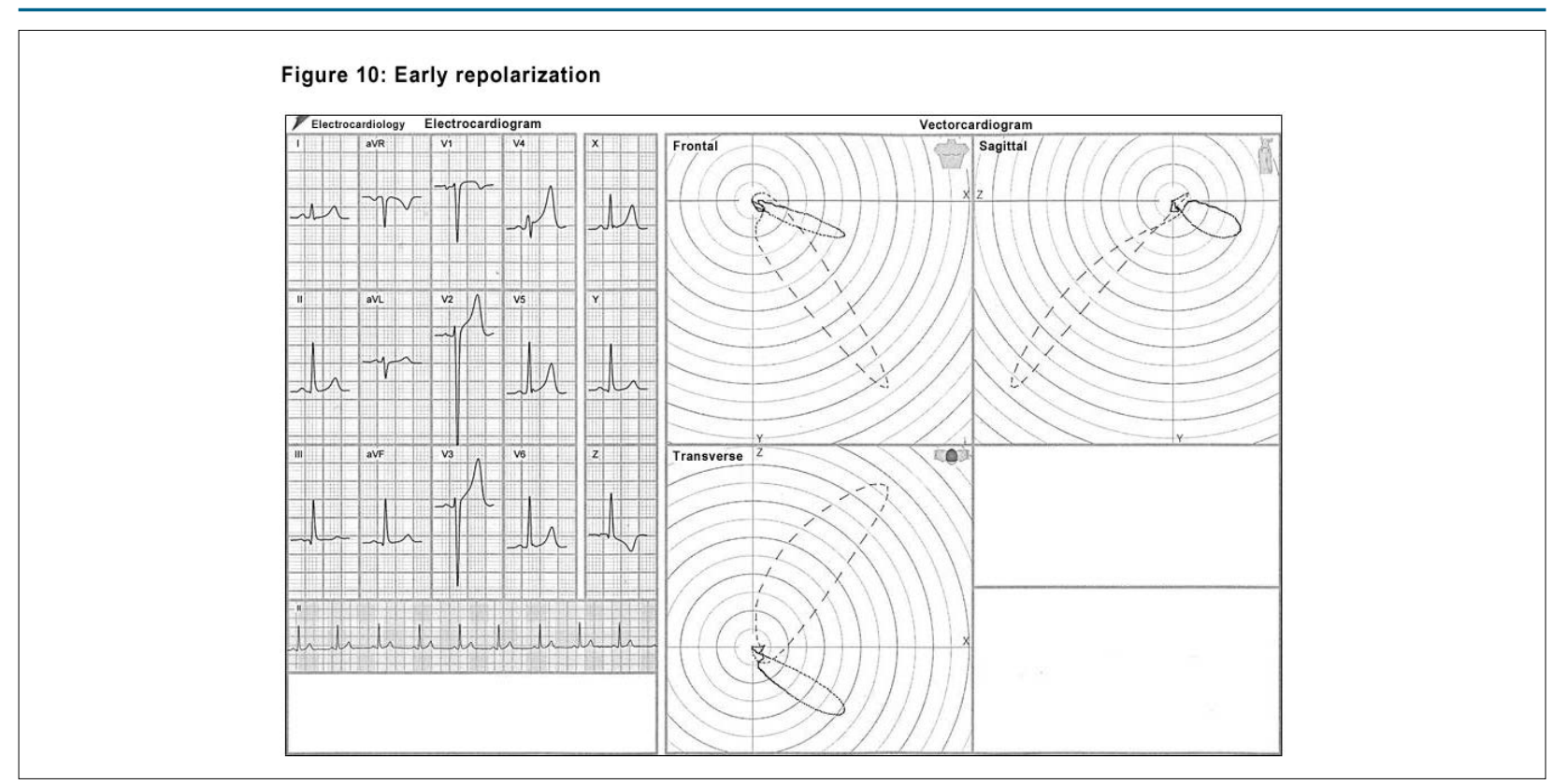

Figure 10 - Characteristic electro-vectorcardiographic aspects of the early repolarization (ER) pattern: Transverse plane: QRS loop onset with counterclockwise rotation; the ECD began posteriorly and ended anteriorly and in the left quadrant in all ER patients. At the terminal segment of the QRS loop (now with clockwise rotation), $100 \%$ of the ER group showed, at the end of QRS loop, a "fishhook" pattern.

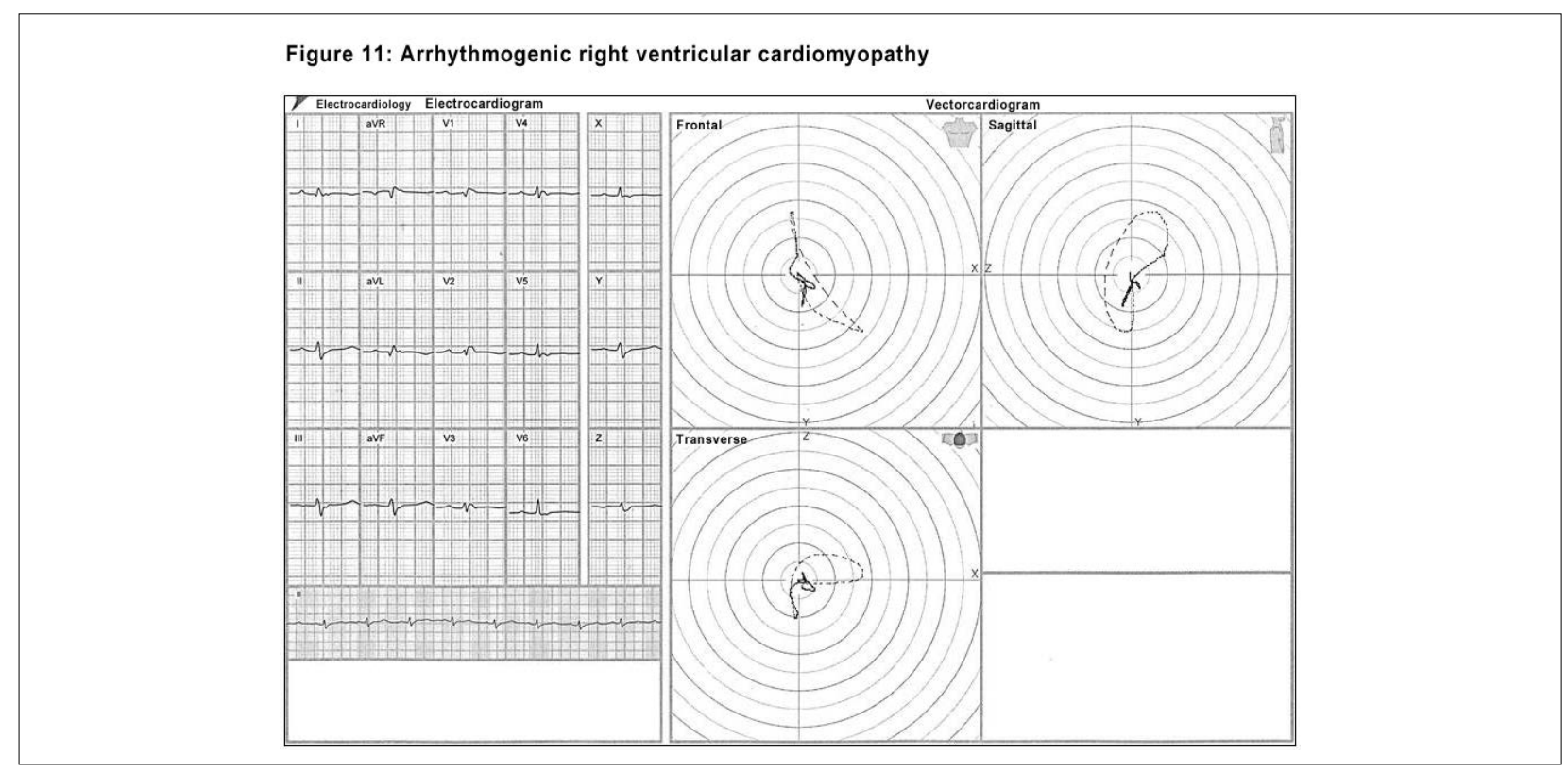

Figure 11 - Electro-vectorcardiographic aspects found in ARVC, displaying the extremely long conduction delay at the end of the QRS loop. 
Figure 12: Electo-vectorcardiographic evaluation of RF ablation in Brugada syndrome
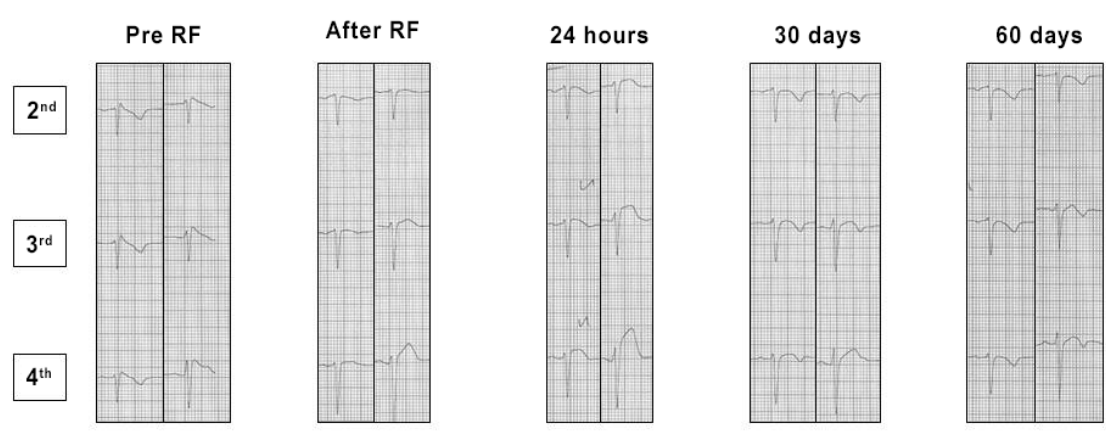

\section{Pre RF}

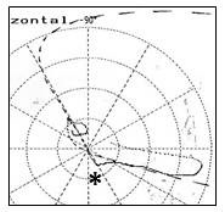

After RF

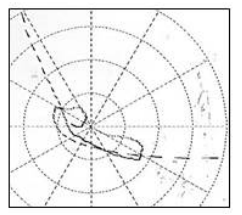

24 hours

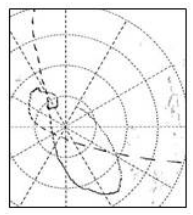

30 days

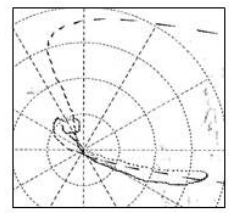

60 days

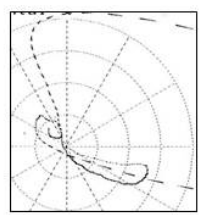

Figure 12 - Evolution of the electro-vectorcardiographic aspects after radiofrequency ablation over time in a patient with ECG-type 1 pattern of Brugada syndrome.

\section{References}

1. Moffa PJ, Sanches PCR. Eletrocardiograma normal e patológico. 7a. ed. São Paulo: Rocca; 2001.

2. Strauss DG, Olson CW, Wu KC Heiberg E, Persson E, Selvester RH, et al. Vectorcardiogram synthesized from the 12-lead electrocardiogram to image ischemia. J Electrocardiol. 2009;42(2):190-7.

3. Bayes de Luna A. Clinical electrocardiography: a textbook. 4th. ed. New Jersey: Wiley-Blackwell; 2012.

4. Pastore CA, Samesima N, Munerato R. ABC do ECG. 3a a ed. São Paulo: Medcel; 2013.

5. Gussak I, Antzelevich C, Wilde AAM, Powell BD, Ackerman MJ, Shen WK. Electrical diseases of the heart. London: Springer-Verlag; 2008. v.1.

6. Moss AJ. Can long QT syndrome be diagnosed by vectorcardiography when the corrected QT on the resting 12-lead electrocardiogram is of normal duration? Heart Rhythm. 2017;14(6):900-1.

7. Cortez D, Schlegel TT, Ackerman MJ, Bos JM. ECG-derived spatial QRS-T angle is strongly associated with hypertrophic cardiomyopathy. J Electrocardiol. 2017;50(2):195-202.

8. Pastore CA, Samesima N, Tobias N, Pereira Filho HG. Eletrocardiografia atual: curso do serviço de eletrocardiografia do inCor. 3ํ. ed. São Paulo: Atheneu; 2016.

9. Pastore CA, Samesima N, Pereira Filho HG, Madaloso BA. Controversial and similar aspects of the Brugada and J wave patterns: the vectorcardiogram point of view. J Electrocardiol. 2016;49(3):439-45.

10. Lingman M, Hartford M, Karlsson T, Herlitz J, Rubulis A, Caidahl K, et al. Value of the QRS-T area angle in improving the prediction of sudden cardiac death after acute coronary syndromes. Int J Cardiol. 2016 Sep $1 ; 218: 1-11$.
11. Hurst JW. Methods used to interpret the 12-lead electrocardiogram: pattern memorization versus the use of vector concepts. Clin Cardiol. 2000;23(1):4-13.

12. Chou TC. When is the vectorcardiogram superior to the scalar electrocardiogram? J Am Coll Cardiol. 1986;8(4):791-9.

13. Man S, Maan AC, Schalij MJ, Swenne CA. Vectorcardiographic diagnostic \& prognostic information derived from the 12-lead electrocardiogram: historical review and clinical perspective. J Electrocardiol. 2015;48(4):463-75.

14. Sedaghat G, Ghafoori E, Waks JW, Kabir MM, Shvilkin A, Josephson ME, et al. Quantitative assessment of vectorcardiographic loop morphology. J Electrocardiol. 2016;49(2):154-63.

15. Carvalho Filho ET, Moffa PF, Pastore CA, Curiati JÁ et al. Vectorcardiographic study of normal aged subjects. Arq. Bras. Cardiol. 1987;48(4):211-6.

16. Sederholm M. The origin of monitoring of acute myocardial infarction with continuous vectorcardiography. J Electrocardiol. 2014;47(4):418-24.

17. Correa R, Arini PD, Correa LS, Valentinuzzi M, Laciar E. Identification of patients with myocardial infarction. Vectorcardiographic and electrocardiographic analysis. Methods Inf Med. 2016;55(3):242-9.

18. Warner RA, Battaglia J, Hill NE, Mookherjee S, Smulyan H. Importance of the terminal portion of the QRS in the electrocardiographic diagnosis of inferior myocardial infarction. Am J Cardiol. 1985;55(8):896-9.

19. Pastore CA, Moffa PJ, Tobias NMO, Moraes AP, Nishioka SA, Chierighini JEC, et al. Bloqueios divisionais do ramo direito e áreas eletricamente inativas. Diagnóstico diferencial eletro-vetocardiográfico. Arq. Bras. Cardiol. 1985;45(5):309-17.

20. Tobias NMMO, Pastore CA, Moffa PJ, Moraes AP, Lima EV, Del Nero Jr E, et al. Bloqueios divisionais do ramo direito na miocardiopatia chagásica. Arq. Bras. Cardiol. 1986;47(6):387-91. 


\section{Review Article}

21. Acunzo RS, Konopka IV, Sanchéz RA, Pizzarelli N, Wells FC, Baranchuk A, et al. Right bundle branch block and middle septal fiber block with or without left anterior fascicular block manifested as aberrant conduction in apparent healthy individuals: electro-vectorcardiographic characterization. J Electrocardiol. 2013;46(2):167-72.

22. Tranchesi J, Moffa PJ, Pastore CA, Carvalho Filho ET, Tobias NMM, Scalabrini Neto A, et al. Bloqueio da divisão anteromedial do ramo esquerdo do feixe de His nas coronariopatias: caracterização vectorcardiográfica. Arq. Bras. Cardiol. 1979;32(6):355-60.

23. Pastore CA, Moffa PJ, Grinberg M, Verginelli G, Ebaid M, Tranchesi J. Bloqueio da divisão posteroinferior em pós-operatório de comissurotomia aórtica e ressecção de anel fibroso subvalvar. Correlação com bloqueio atrioventricular total (relatos de casos). Arq. Bras. Cardiol. 1979;32(5):303-7.

24. Moffa PJ, Ferreira BMA, Sanches PCR, Tobias NMM, Pastore CA, Bellotti G. Bloqueio divisional anteromedial intermitente em paciente com insuficiência coronária. Arq Bras Cardiol. 1997;68(4):293-6.

25. Pastore CA, Samesima N, Kaiser E. Vectorcardiographic patterns for differential diagnosis in right end-conduction delay, early repolarisation and Brugada syndrome. J Electrocardiol. 2012; 46:e1-e37.

26. de Micheli A, Iturralde P, Medrano GA. On the electrical manifestations of some heart diseases associated with ventricular preexcitation. Arch Cardiol Mex. 2006;76(Suppl 4):S137-43.
27. Titomir LI, Trunov VG, Aidu EA, Sakhnova TA, Blinova EV. New approaches to the diagnosis of left and right ventricular hypertrophy by means of dipolar electrocardiotopography. Anadolu Kardiyol Derg. 2007; 7(Suppl 1):29-31

28. Pérez-Riera AR, Barbosa-Barros R, Daminello-Raimundo R, de Abreu LC, Tonussi Mendes JE, Nikus K. Left posterior fascicular block, stateof-the-art review: a 2018 update. Indian Pacing Electrophysiol J. $2018 ; 18(6): 217-30$.

29. Samesima N, Pastore CA, Facin ME. Brugada syndrome ablation: what the vectorcardiogram can tell us? ICE/2017. Portland, EUA [Abstract]. Disponível em: www.electrocardiology.org/images/conferences/ICE_2017/ schedule_2017-06-28.pdf.

30. Pastore CA, Samesima N. Brugada and J wave patterns: the role of vectorcardiography in distinguishing them. In: Brugada after RF ablation: what the vectorcardiogram can tell us? [citado 25 mar. 2019]. Disponível em: www.electrocardiology.org/images/Presentations/VCG-BrugadaPastore.pdf.

\section{Appendix}

For additional information, please see the online version of this article. 